\title{
The Digital Etiquette Enhancing to Global Citizenship of Social Studies Teachers in a New Normal Society
}

\author{
Charin Mangkhang ${ }^{1} \&$ Nitikorn Kaewpanya ${ }^{1}$ \\ ${ }^{1}$ Faculty of Education, Chiangmai University, Chiang Mai, Thailand \\ Correspondence: Charin Mangkhang, Faculty of Education, Chiang Mai University, 239 Huay Kaew Rd, Suthep, \\ Mueang District, Chiang Mai, 50200, Thailand. E-mail: charin.mangkhang@cmu.ac.th
}

Received: June 24, 2021

doi:10.5539/hes.v11n3p89
Accepted: July 20, $2021 \quad$ Online Published: July 28, 2021

URL: https://doi.org/10.5539/hes.v11n3p89

\begin{abstract}
The world is transforming into a post-digital society, as a result, people gain the freedom to communicate, share values and knowledge in a society without borders. The virtual world has become a social interaction space while being integrated to enhance the life quality of citizens in many organizations, such as online class management, health management, and poverty alleviation. From the current circumstances, numerous online users still lack responsibility in handling social media which can cause widespread impact. The study of the digital etiquette of world citizens in a new normal society will provide good practice for effective use of the online space in the digital world of global citizens.
\end{abstract}

Keywords: digital etiquette, global citizenship, social studies teachers, new normal society

\section{Introduction}

Modernism and Neo-Humanism have boosted inquiries regarding the saturation point of the upcoming digital age. Advanced technology is degrading human values while decreasing people's awareness of social participation resulting in the concept of a Post Digital Society that aims to present an alternative perspective between humans and technology (Knox, 2019). This starts the challenge to study the advancement and efficiency of future technology that has to convert the people perspective to be more "natural" and "human being". Consequently, they can live in the midst of disruptive technologies to drive equal humanity in the society of the future.

The world is moving towards a world without borders consequently people can rapidly access information and communication with ease. Modern technology media play a crucial part in people's lives of all ages, especially teenagers. The various media and information technology are widely adopted through communication devices such as TVs, phones, tablets, computers, etc. (National Statistical Office, 2018). The use of digital technology is part of human behavior which is greater and influenced by beliefs and values as defined by most societies. The survey results from the Basic Education Commission on the use of technology for education suggest that technology can increase educational opportunities to be convenient, rapid, up-to-date, and thorough for the students of all ages and educational systems either formal education, non-formal or informal education. Technology, if correctly used, can benefit as a tool for effective teaching while creating equality to gain knowledge from various convenient, fast, and up-to-date world information without limitations in learning (Ministry of Education, 2015). From the research study on digital skills, world citizens under the age of 18 today were born and raised with information technology that facilitates their lives. Therefore, their lives are in line with the use of information technology, such as studying, communication, and the exchange of goods and services, etc. Finally, these world citizens will grow up to be the main force of the global society in the future.

The changes of the world and Thailand as a result of the rapid advancement of digital technology and internet networks communication affecting the behavior of creating, using, and communicating information of people in society. The use of digital information for compiling, modifying, duplicating, and sharing by posting information can be simply performed at home, at work, in the classroom, or even in public places. From society's perspective, such activities should be conducted under the law considering various appropriateness. Nevertheless, the inappropriate dissemination of digital information has been always found without realizing the wrongdoing. Since digital media can drive the development of people's learning and economic and social development, people in society require to gain knowledge and understand digital media transmission. The digital media management and information technology processes, including managing emotions in social media, are considering a Digital 
Literacy (DL) (Leenaraj, 2017). In addition to digital literacy, one essential use of information technology and social interaction is "Digital etiquette". This can be considered as an important guide to the effective use of the social space which can help to reduce the number of wrongdoings in social media and stabilize the online society in the post-digital era to make it suitable for future world citizens.

Digital etiquette is a standard of conduct on social media and a norm for the use of digital technology, online engagement, including social interactions in the virtual world. Digital etiquette encourages proper behavior and the process of using technology in the classroom for learning by considering the separate parts of the inappropriate and irresponsible use of technology. For example, the Digital Etiquette Guidelines create awareness that students should keep their cell phones in silent mode to not disturb during class teaching. Additionally, the guidelines can help training about treating other online users with respect and courtesy and not violating privacy rules (Ribble, 2015; Nordin et al., 2016).

Global citizens in the dimension of Digital Citizenship are people who have the ability to use the Internet to manage, control, self-regulate, conscience, and up-to-date. It is the norm to use digital technology properly and responsibly and learn how to use technology smartly and safely. Digital citizens are required to aware of the opportunities and risks in the digital world as well as understanding rights and responsibilities in the online world (Chusangnin, 2019). Digital citizenship is one of the standards in education technology in the Thailand 4.0 era aiming to nurture citizens to demonstrate their understanding of social, cultural, and human issues related to information technology while behave ethically according to the law to use information safely and legally. It is the ability to safely use digital technology and media with responsibility, and ethics (Mangkhang, 2016).

As a result, it is necessary among social studies teachers to prepare citizens for the change in future societies to be appropriate information technology users to create a livable and peaceful online community. In addition, the development of digital etiquette also aids in managing the issues of cyberbullying, network security, privacy, and digital traces, etc. that occur in the world and Thai society today. Finally, it will help promote global and Thai citizens to have the ability to manage themselves to keep up with the media, including creatively and safely use the information technology.

\section{Digital Etiquette: Active Digital Citizen}

Digital Citizenship is a person who can effectively use digital and social media with the understanding of the rights and responsibilities in the online world while maintaining ethics and safety for using digital technology and aware of the opportunities and risks in the digital world (Chaowakeeratiphong \& Wongnaya, 2020). A skillset and knowledge of technological and advanced thinking are required to be a good digital citizen. This is called "digital literacy" which takes advantage of the information in the cyber world and knows how to protect yourself from various risks in the online world. The right, responsibility, and ethics have to be recognized in the digital era and take advantage of the Internet for political, economic, and social-cultural participation for self, community, country, and the world (Wongkitrungruang, 2018). Besides knowledge and digital skills, the future digital citizen necessity realizes the importance of using online spaces as a public space with free speech for everyone to express their opinions, share information and disseminate news. Noted that the online space is still a shared space where everyone can share. Therefore, a guideline or digital social norms are required to help regulate the use of such online spaces without threatening privacy or create insecurity for users.

In the past, the term "Digital etiquette" had not yet emerged, the term "Digital literacy" or "Digital skills" were more commonly observed. Gilster (1997), a scholar who studies early digital literacy, defined digital literacy as an ability to understand the use of information and covers people's understanding of working with various digital information resources. In addition, William and Minnian (2007) suggested that digital literacy is a broad concept focusing on generating knowledge from various sources. Critical thinking meets computer literacy with an emphasis on information technology skills. From the study, many scholars often mention ethics, responsibility, or awareness of using online space or digital technology included in the knowledge or digital skills that are not explicitly stated in the code of conduct or appropriate guidelines on ethics or the suitability of using the digital space. We, therefore, proposed the term "Digital Etiquette" discussing key norms, practices, and guidelines that will enable digital citizens to use appropriate digital technology leading to the production of a creative online space.

Therefore, digital etiquette is a creation of an online social norm in the form of a legal framework, social structures, standards, or rules of appropriate behavior in the context of a digital environment including public awareness regarding the use, transmission, and dissemination of electronic information. It also includes academic ethics in a digital context where information can be rapidly disseminated. Currently, it is widely spread during epidemic situations that directly affect communication and changing social interactions. Maintaining 
digital etiquette is hence a public consciousness and the responsibility for using the social space to reduce the impact of information technology usages that occurs considerably in the global and Thai society. It is an important criterion that will lead to the development of global citizenship to be ready for a society without borders in the future (Shea, 1994; Ribble, 2015; Nordin et al., 2016).

So, an active digital citizen is a digital citizen who is aware of the thoughtful use of public spaces with others in the online community with scope for freedom of expression, information sharing, and access, including personal privacy information security, and others. In addition, active digital citizens do not use online space to harass or causing damage to any individuals and society. An active digital citizen requires knowledge, skills, and digital etiquette that will be the foundation of use, transmission, and decision-making in the context of the digital space.

\section{Conceptual Framework "Digital Etiquette"}

The study from Gilster (1997), Soby (2003), Martin (2006), Bowden (2007), and Cordell (2013) presented the concept of digital literacy to build competency and skill of digital citizen as shown in Figure 1.

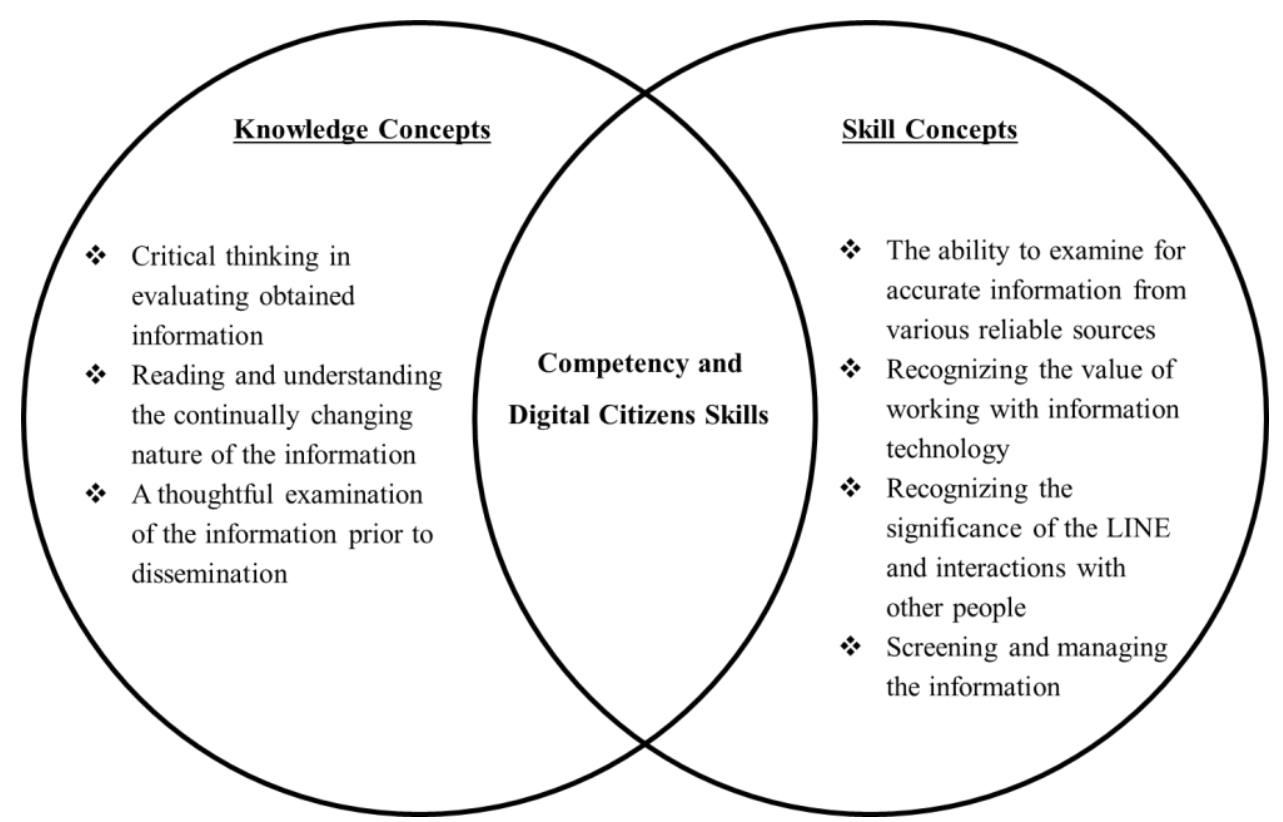

Figure 1. Analyzing the concept of digital literacy into competence and skills for digital citizen

Source: Charin Mangkhang and Nitikorn Kaewpanya

Additionally, Bowden (2007) suggested that digital literacy is a broad concept associating various related knowledge. The competence and skills of computers including information and communication technology are the key fundamentals. Moreover, the social skills in evaluating information should be emphasized. All of these form a collection of knowledge, understanding, and attitude. From the study of the aforementioned conceptual framework, it can be concluded that digital citizens are required the digital literacy, digital skills, and digital etiquette. The details are as follows:

1. Digital knowledge is essential knowledge in a digital context aiming to create knowledge concerning appropriate and effective technology selection and presenting information with judgment and up-to-date, etc.

2. Digital skills are the ability to apply information technology and communication, knowledge management, digital information communication and dissemination, and systematic thinking processes, etc.

3. Digital etiquette is the public awareness of the use of information and communication technology with an awareness of information security and privacy data. An online space should be perceived as a public space shared with other people in society with the boundaries for use and shared good practice. This can be summarized in a diagram as shown in Figure 2. 


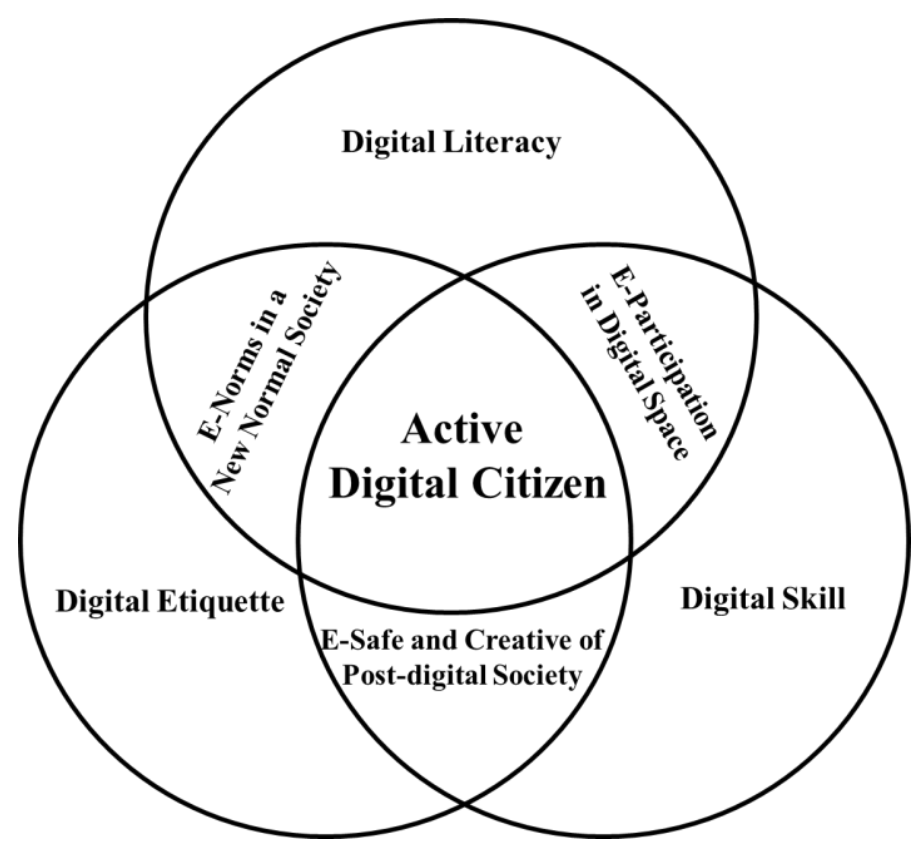

Figure 2. Features of Active Digital Citizen in New Normal Society

Source: Charin Mangkhang and Nitikorn Kaewpanya

The character of digital citizenship in a new normal society is to recognize a fundamental digital space or social media as a public space in the actual world. Any action in the digital space is like acting in the social realm which can encourage citizens to be aware of their roles and duties in maintaining order in social media.

\section{Digital Etiquette: Disruptive Social Etiquette}

Etiquette is used as polite and appropriate behavior or empirical verbs for the situation. It is a relationship between people and acceptable practices in that society (Kongjan, Doungphummes, \& Bhibulbhanuvat, 2021). Basically, etiquette is behavioral patterns validated by society and passes along as social norms to the next generations. Etiquette is a culture that can change over time while etiquette in disruption society has emerged in the post-digital era. Behavior that contradicts the traditional etiquette in the Thai education system toward social, religion, and culture can be seen in the following example:

\subsection{Dining Etiquette}

In Thai etiquette, talking while eating is considered inappropriate for reasons of modesty and food choking prevention. Nevertheless, one type of popular occupation that arises from this social norm currently is a food review Youtuber who eats different kinds of food and describing the taste, deliciousness, as well as how one's feelings towards that type of food during eating. In this case, it is necessary to rethink the norms of table etiquette in a new normal of society.

\subsection{Propriety to Communicate}

This has long been a social norm for communicating with others to respect their privacy and a good time to communicate, such as sending a letter every month, making phone calls when necessary for work, or an emergency. However, nowadays communication is extremely convenient, people can make communication at any time. Although we can communicate at any time, we should consider the time appropriately, such as contact during office hours or contact only important matters except in the group of friends or social groups that can communicate in a friendly style. The time arrangement and the appropriateness of communication in each social group will help make the use of communication technology more creative.

\section{Guidelines for Digital Etiquette Enhancing to Global Citizenship of Social Studies Teachers in a New Normal Society}

The propose a new approach to promoting digital etiquette for a new normal society in view of the future of digital citizenship for social studies teacher divided into 3 levels: (Shea, 1994; Gilster, 1997; Soby, 2003; Martin, 2006; Bowden, 2007; Ribble, 2015; Cordel, 2013; Nordin, et al., 2016; Mangkhang, 2016; Akhwani, 2019). 


\subsection{Individual Level}

Judgment should be made for disseminating your personal information in the public world and pay attention to the dissemination of information that may pose a threat to your privacy also realize "There is no real public space and there is no permanent pinning area."

Information should be analyzed between right or wrong, safe or dangerous that poses a threat to the safety of yourself and others such as fake news, money transfer channels in various cases, etc.

Usage time for digital devices should be managed while balancing the use of online and real space.

Digital footprints from other online users should be managed which require an understanding of the nature of living in the digital world to always leave traces of information. Social studies teacher should be aware that other people's digital footprints are personal and should not access them unnecessarily without permission.

Communicate or conversation should be polite and do not communicate with obscene language, sexual harassment, or demonstrating power intimidation.

Attire in online public spaces should be appropriate for the occasion with the thought that the online space is also a form of public space.

\subsection{Social Group Level or a Specific Network}

Online harassment should be recognized and dealt with intelligently while being discreet for digital communication by not creating or disseminate false or harassing information that threatening others on social media.

Sharing information in the digital world should use polite factual information. A personal opinion or emotions should be reserved and creatively express with no sarcasm or pinch to damage.

Online networks should not be used as a tool to defraud others or doing any illegal actions, such as setting up a chain-sharing group, sex video sales, or cyberbullying groups.

Social studies teacher should not tease, humiliate, slander, scandal, abuse or bully others on social media for entertainment online.

Social studies teacher should build a creative social network and share a happy space together.

\subsection{Public Level}

The problem of social bullying should not be ignored and we should mutually create a creative online public space.

False information should not be disseminated or pose a threat that will harm others and does not publish other people's digital footprints in public areas.

In the online world, conflicting opinions tend to be more courageous to express their opinions online than in real life because they do not concern about the relationship. Therefore, conflicting opinions must be expressed critically with rational discussion without emotional expression.

For disseminating personal information in public space, we should always be aware that everyone can comment, remark, or question. Therefore, personal information must be disseminated with discretion and good judgment.

Information from other people should not be copied, modified, and disseminated as your own which is considered an offense under the law.

The guideline to apply digital etiquette in a new normal society depends on the context of that local area including the interaction relationship between people or groups. In addition, digital etiquette should be cultivated at the level of family, school, and social organizations. To apply digital etiquette on social media in real life, cooperation from all sectors is required to promote digital etiquette to the new citizen in a future new normal society.

\section{Conclusion}

Digital etiquette is an essential social norm that necessity be introduced to the citizens of a new normal society. The good etiquette from the social studies class of the education system is no longer following the traditional norms. Daily etiquette, people interaction, and real-life proportions are shared with online life. A hybrid life of digital citizens or living in both worlds can often confuse applying digital etiquette or skill between real life and virtual life online. Essentially, social studies teacher should be understood and cultivated from the family level to develop citizens to grow into quality digital citizens to further create a safe and creative society. 


\section{References}

Akhwani, A. (2019). Strategy of Digital Etiquette Education of Elementary School Students. PrimaryEdu-Journal of Primary Education, 3(2), 43-54. https://doi.org/10.22460/pej.v3i2.1378

Bowden, D. (2007). Origins and concepts of digital literacy. New York: Lang Pub.

Chaowakeeratiphong, T., \& Wongnaya, S. (2020). Guidelines to Develop Digital Citizenship of Students at the Faculty of Education, Kamphaeng Phet Rajabhat University. The Golden Teak: Humanity and Social Science Journal, 26(4), 72-85.

Chusangnin, C. (2019). Digital intelligence. Retrieved from https://www.scimath.org/article-technology/item/10611-digital-intelligence

Cordell, R. (2013). Information literacy and digital literacy: Competing or complementary?. Communication in Information literacy, 7(2), 177-183. https://doi.org/10.15760/ comminfolit.2013.7.2.150

Gilster, P. (1997). Digital literacy. New York: John Wiley \& Son.

Hargittai, E. (2005). Survey measures of web-oriented digital literacy. Social Science Computer Review, 23(3), 371-379. https://doi.org/10.1177/0894439305275911

Knox, J. (2019). What Does the 'Postdigital' Mean for Education? Three Critical Perspectives on the Digital, with Implications for Educational Research and Practice. Postdigital Science and Education, 1(1), 357-370. https://doi.org/10.1007/s42438-019-00045-y

Kongjan, K., Doungphummes, N., \& Bhibulbhanuvat, S. (2021). Communication Etiquette for Thais' Usage of Social Media. Parichart Journal, 34(1), 155-175.

Leenaraj, B. (2017). Digital literacy skill for developing learning quality. Thai Library Association, 61(2), 76-92.

Mangkhang, C. (2016). Futurology: Theory and Techniques for Social Studies Learning Management. Chiangmai: Diamond graphic group.

Martin, A. (2006). Literacies for the digital age. London: Facet Pud.

Ministry of Education. (2015). Policy of the Minister of Education. Bangkok: Office of the Permanent Secretary, Ministry of Education.

National Statistical Office of Thailand. (2018). Household Information and Communication Technology Survey. Retrieved from http://www.nso.go.th/ sites/2014/Pages/News/2561/N26-10-61.aspx

Nordin, M., Ahmad, T., Zubairi, A., Ismail, N., Rahman, A., Trayek, F., \& Ibrahim, M. (2016). Psychometric properties of a digital citizenship questionnaire. International Education Studies, 9(3), 71-80. https://doi.org/10.5539/ies.v9n3p71

Ribble, M. (2015). Digital Citizenship in Schools: Nine elements all students should know (3rd ed.). ISTE.

Shea, V. (1994). Netiquette. San Francisco: Albion Books.

Soby, M. (2003). Digital competence- from education policy to pedagogy: The Norwegian context. New York: Lang Pub.

William, P., \& Minnian, A. (2007). Exploring the challenges of developing digital literacy in the context of special education needs. Australia: Auslib Pr.

Wongkitrungruang, W. (2018). Digital Citizenship. Bangkok: Digital Economy Promotion Agency, Ministry of Digital Economy and Society.

\section{Copyrights}

Copyright for this article is retained by the author(s), with first publication rights granted to the journal.

This is an open-access article distributed under the terms and conditions of the Creative Commons Attribution license (http://creativecommons.org/licenses/by/4.0/). 